\title{
Prospective evaluation of biodegradable polymeric sealant for intraoperative air leaks
}

Bernard J. Park ${ }^{1 *}$, John M. Snider ${ }^{2}$, Nathan R. Bates ${ }^{3}$, Stephen D. Cassivi ${ }^{4}$, G. Kimble Jett ${ }^{5}$, Joshua R. Sonett ${ }^{6}$ and Eric M. Toloza ${ }^{7}$

\begin{abstract}
Background: A biodegradable polymeric sealant has been previously shown to reduce postoperative air leaks after open pulmonary resection. The aim of this study was to evaluate safety and efficacy during minimally invasive pulmonary resection.

Methods: In a multicenter prospective single-arm trial, 112 patients with a median age of 69 years (range 34-87 years) were treated with sealant for at least one intraoperative air leak after standard methods of repair (sutures, staples or cautery) following minimally invasive pulmonary resection (Video-Assisted Thoracic Surgery (VATS) or Robotic-Assisted). Patients were followed in hospital and 1 month after surgery for procedure-related and device-related complications and presence of air leak.

Results: Forty patients had VATS and 72 patients had Robotic-Assisted procedures with the majority (80/112, 71\%) undergoing anatomic resection (61 lobectomy, 13 segmentectomy, 6 bilobectomy). There were no device-related adverse events. The overall morbidity rate was 41\% (46/112), with major complications occurring in 16. 1\% (18/112). In-hospital mortality and 30-day mortality were 1.9\% (2/103). The majority of intraoperative air leaks $(107 / 133,81 \%)$ were sealed after sealant application, and an additional 16\% (21/133) were considered reduced. Forty-nine percent of patients (55/112) were free of air leak throughout the entire postoperative study period. Median chest tube duration was 2 days (range 1 - 46 days), and median length of hospitalization was 3 days (range 1 - 20 days).
\end{abstract}

Conclusions: This study demonstrated that use of a biodegradable polymer for closure of intraoperative air leaks as an adjunct to standard methods is safe and effective following minimally invasive pulmonary resection.

Trial registration: ClinicalTrials.gov: NCT01867658. Registered 3 May 2013.

Keywords: Lung cancer, Lung surgery, Video-assisted thoracic surgery, Robotic surgery, Intraoperative air leak, Postoperative air leak, Pleural air leak sealant

\section{Background}

Lung cancer remains a common and deadly problem both in the United States and worldwide [1]. When indicated, primary surgical resection remains one of the most effective treatments for lung cancer and other isolated pulmonary conditions. Limiting postoperative morbidity in patients undergoing pulmonary resection results in

\footnotetext{
* Correspondence: parkb@mskcc.org

${ }^{1}$ Memorial Sloan Kettering Cancer Center, 1275 York Avenue, Box 531, New York, NY 10065, USA

Full list of author information is available at the end of the article
}

decreased length of stay and reduced healthcare costs.[2] One strategy to reduce postoperative complications has been through the utilization of minimally invasive surgery (MIS) approaches, such as Video-Assisted Thoracic Surgery (VATS) and Robotic-Assisted. Multiple studies have shown that MIS pulmonary resection has benefits over a traditional thoracotomy approach, such as decreased length of stay, decreased short-term postoperative pain and fewer complications [3-6]. As a result, the utilization of VATS and Robotic-Assisted for anatomic resection has steadily increased [7]. In a recent review of the voluntary 
Society of Thoracic Surgery (STS) general thoracic surgery database, the rate of utilization of thoracoscopic approaches for lobectomy between 2000 and 2010 was approaching nearly $50 \%$ [8].

While increasing utilization of MIS approaches reduces overall complication rate and length of stay, one of the most common adverse events following lung resection remains prolonged air leak $[9,10]$. Outside of major cardiopulmonary events, air leak management is one of the most significant causes of protracted hospital stay and cost [11]. Reflective of the impact of the problem, there have been generations of research and product development in order to achieve meaningful reduction in air leak rates. Early studies utilizing both routine and selective use of fibrinbased sealants showed no difference in duration of leak, chest tube duration, or length of stay [12-14]. The next generations of sealants were based on the use of a synthetic, water-soluble polyethylene glycol (PEG) derivative. The first approved by the FDA utilized a PEG gel applied to the lung surface and photopolymerized for postoperative pneumostasis and was shown in a multicenter, prospective randomized trial to be associated with a higher rate of patients remaining free of air leaks postoperatively [15]. The product is no longer available in the United States.

Subsequently, a polymeric biodegradable sealant that did not require light activation was developed by combining a PEG-based crosslinker, functionalized with succinate groups (PEG-(SS) $)_{2}$, with human serum albumin-USP just prior to usage (Progel ${ }^{\mathrm{TT}}$ Pleural Air Leak Sealant (PALS), Bard Davol, USA) [16]. Once mixed, Progel ${ }^{\mathrm{Tu}}$ PALS polymerizes to form a clear, flexible hydrogel matrix that adheres to the lung tissue within $15 \mathrm{~s}$ and forms a flexible seal that can withstand $30 \mathrm{mmHg}$ air pressure within $2 \mathrm{~min}$ of application and a maximum burst pressure of greater than $90 \mathrm{mmHg}$ in less than $10 \mathrm{~min}$. The material is completely reabsorbed within 1 month postoperatively. When Proge ${ }^{\mathrm{Tm}}$ PALS was evaluated in a multicenter, prospective randomized trial for treatment of intraoperative air leaks following open pulmonary resection, its use was associated with a higher rate of intraoperative sealing, a lower rate of postoperative air leaks, and reduced hospital stay [17]. Based on these data, Progel ${ }^{\mathrm{ms}}$ PALS remains the only FDA-approved pneumostatic agent.

Despite data showing the efficacy of Progel ${ }^{\mathrm{m}}$ PALS in reducing intraoperative and postoperative air leaks following open pulmonary resection, there are little data on its use during minimally invasive approaches, such as VATS or Robotic-Assisted procedures. The purpose of this multicenter, prospective study was to evaluate the safety and efficacy of Progel ${ }^{\text {Tw }}$ PALS for sealing air leaks incurred during MIS pulmonary resection.

\section{Methods}

This study was conducted in compliance with the United States Code of Federal Regulations (CFR), 21 CFR Part
812, Investigational Device Exemptions, Part 56, Institutional Review Boards, Part 50, Protection of Human Subjects, and the ethical principles that have their origin in the Declaration of Helsinki. Institutional review boards at each institution approved the clinical trial prior to initiation of the study. Informed consent was obtained in writing from all patients.

Patients 18 years old and older, who were scheduled for a MIS lung resection (wedge resection, lung volume reduction surgery, segmentectomy, lobectomy, or bilobectomy), decortication, or biopsy by VATS or RoboticAssisted approach and who gave informed consent, were evaluated for entry into the study. Patients had to have at least one visible intraoperative air leak (IOAL) at the completion of the procedure following standard closure methods, including but not limited to suturing or stapling. Exclusion criteria included: pregnancy, breast feeding, known sensitivity to human albumin, history of a previous lung resection or previous use of sealant for air leaks, renal insufficiency with a baseline serum creatinine $\geq 2.5 \mathrm{mg} / \mathrm{dl}$ or active dialysis, active or latent infection which was systemic or at the intended surgical site, inability to apply standard closure methods, or the presence of a significant clinical disease or condition that might complicate the surgery and make it difficult to evaluate the safety and effectiveness of the sealant.

The study was performed at 15 institutions with a mixture of academic, teaching, and community hospitals. There was a single principal investigator at each site, along with sub-investigators, and each underwent training in preparation and use of the sealant prior to the start of the study. A maximum of 20 subjects were treated at each site. Enrollment was balanced with 40 subjects undergoing VATS and 72 subjects undergoing Robotic-Assisted procedures.

The primary objective was to assess the safety of using the sealant after MIS pulmonary resection, and the primary endpoint was to measure the overall and major postoperative morbidity rates. Complications were considered as a composite rate of device- and procedure-related events and were graded according to the NCI Common Terminology Criteria for Adverse Events (Version 4.03) upon study completion. Prolonged air leak was defined as air leak present after the $5^{\text {th }}$ postoperative day. The secondary objective was to measure efficacy of the sealant for reducing intraoperative and postoperative air leaks. Exploratory endpoints included: the proportion of intraoperative air leaks sealed or reduced; the proportion of patients free of air leaks immediately following surgery in the recovery room; chest tube duration; and length of hospitalization.

After all pulmonary resections were completed, air leaks were identified by inflating the lung and submerging the areas of closure within saline solution (or water) to 
observe for air bubbles. If there were no air leaks detected, the patient was not treated. If air leaks were detected, standard methods of closure, such as additional suturing and stapling, were utilized, and a second leak test was performed. If there were air leaks following standard closure, the location and size of leaks were recorded, and the areas were treated with sealant. After application of the sealant to each of the identified air leaks, ventilation to the treated lung was suspended or reduced for $2 \mathrm{~min}$, a second leak test was then performed, and the existence, location, and size of leaks were again recorded. If an air leak was still present, the investigator was permitted to reapply sealant up to two more times or use other closure methods (e.g., additional sutures or staples, pleural tent, pneumoperitoneum) to close the remaining air leak. Sealant was not applied prophylactically to areas of the lung that were not leaking air at the time of surgery (Fig. 1).

Kits containing the sealant were stored at 2 to $8{ }^{\circ} \mathrm{C}$ prior to usage. Each kit included two glass cartridges (one with human serum albumin-USP and the other with powdered crosslinker PEG), a syringe, and a vial of sterile water to rehydrate the powdered crosslinker just prior to usage. A double-barreled applicator was used for housing the two cartridges with a special tip to facilitate mixing of the components and to spray the mixture onto the lung. Each kit was supplied sterile and contained $4 \mathrm{~mL}$ of sealant.

Chest tubes were placed on 20 to $25 \mathrm{~cm} \mathrm{H}_{2} \mathrm{O}$ suction for $24 \mathrm{~h}$, after which they were placed to water seal if no air leak was detected. If an air leak remained after $24 \mathrm{~h}$, the switch to water seal was done at the discretion of each investigator. The use of digital, regulated intrapleural pressure drains were allowed. Chest tubes were removed when the following occurred: there was no air leak following the switch to water seal; the lung had expanded sufficiently, or in the investigator's opinion, there was no significant increase in the size of a pneumothorax that would prevent removal; and volume of drainage $<5 \mathrm{cc} / \mathrm{kg} / 24 \mathrm{~h}$ or $<2.5 \mathrm{cc} /$ $\mathrm{kg} / 12 \mathrm{~h}$. The duration of Post Operative Air Leak (POAL) was measured from the day of surgery until the chest tube was removed. Air leaks were assessed by qualified hospital staff, including investigators, nurses, study coordinators, physician assistants, and residents. If there were multiple readings at a designated air leak assessment time and a discrepancy was observed between readings, the investigator's assessment was utilized. Chest roentgenograms (CXR) were obtained preoperatively, within $6 \mathrm{~h}$ of surgery, within $24 \mathrm{~h}$ prior to and after chest tube removal, and at 1-month follow-up. Some patients who had a prolonged air leak were discharged from the hospital with the chest tube connected to a Heimlich or Pneumostat ${ }^{\mathrm{Tm}}$ valve. When this occurred, the patient was asked to return weekly for air leak assessment until the chest tube was removed. Chest tube duration was measured from the day of surgery to the day the last chest tube was removed. Patients were followed up at 1 month where they had a physical examination, CXR, and blood tests (blood urea nitrogen, creatinine, glomerular filtration rate) and were questioned about complications since discharge from the hospital.

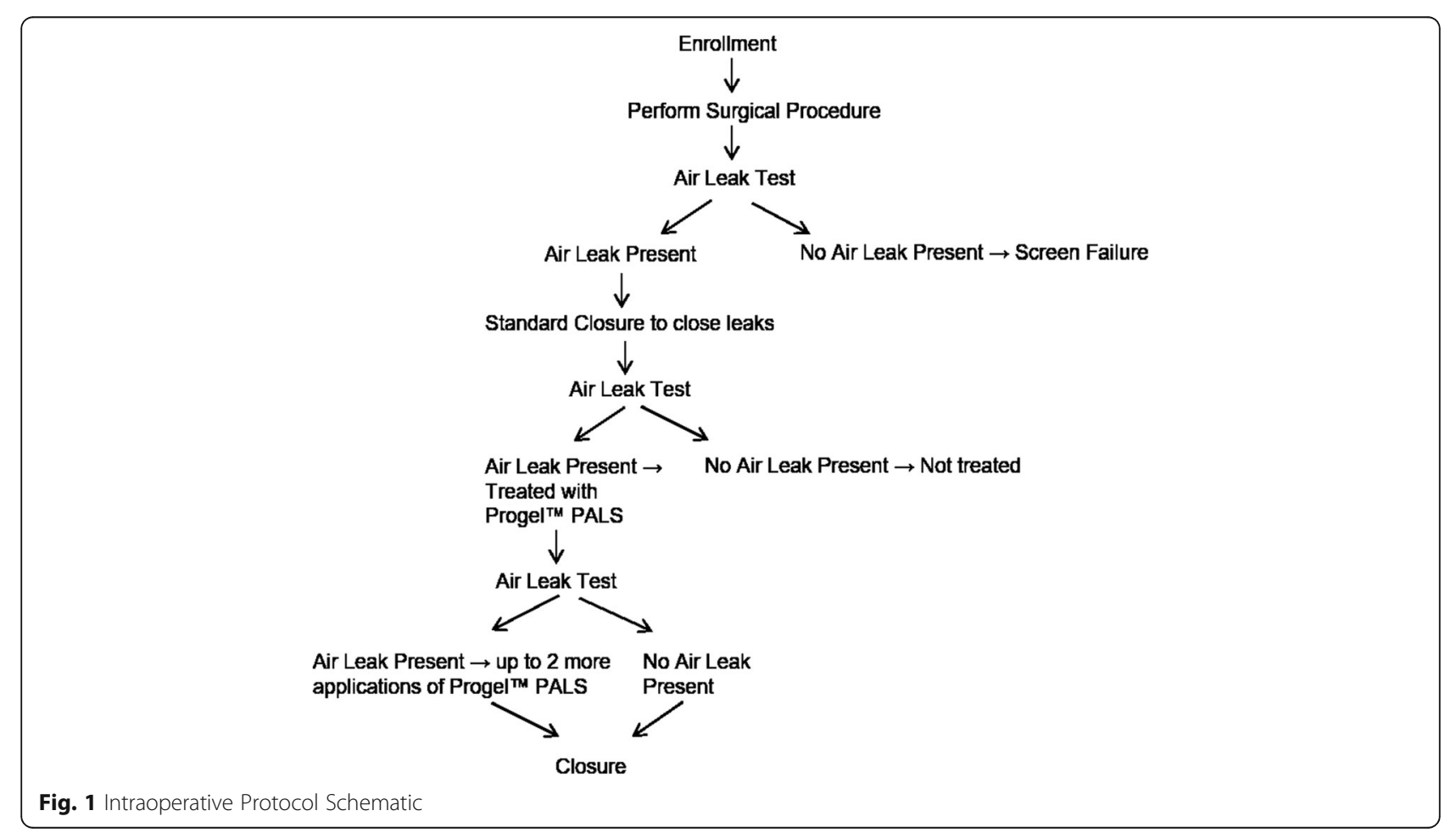


A Clinical Events Committee (CEC) comprised of independent lung surgeons specializing in minimally invasive surgery, adjudicated all adverse events in this study for seriousness and for device and procedure relationship. All protocol-required CXRs were evaluated by an independent core laboratory for changes in lung expansion, presence or absence of pneumothorax, as well as size of pneumothorax.

Statistical analysis was performed using SAS software version 9.3 in accordance with the trial statistical analysis plan. All analyses were based on the modified intent-totreat population that included those subjects who underwent successful VATS or Robotic-Assisted procedure and were treated with sealant. The key secondary endpoint of the study that measures the effectiveness of the treatment was the proportion of subjects without postoperative air leaks following lung surgery up to 1-month follow-up. The study was designed to treat approximately 105 subjects in order to obtain 100 evaluable subjects followed through the 1-month follow-up visit after allowing for 5\% loss to follow-up.

\section{Results}

There were 207 patients screened for participation, and 192 who met baseline eligibility were enrolled. There were 112 patients treated on protocol, and 80 who were not treated. The reasons for not treating these patients are listed in Fig. 2. The most common reason $(n=69)$ was either absence of intraoperative air leak following standard methods of closure or inability to utilize standard closure techniques. All 112 patients were tracked until discharge; however, 9 patients did not complete the trial through the 30-day postoperative time-point following treatment (Fig. 2).

There were 66 women and 46 men evaluated. Demographics and clinical characteristics are listed in Table 1. In general the group had good preoperative lung function, and the most common indication for surgery was a primary lung tumor. The surgical procedures performed are listed in Table 2. The most common operation performed was lobectomy (61/112), and overall anatomic lung resection was performed in $71 \%$ of patients (80/112). Eleven patients underwent more than one pulmonary procedure, but only the most extensive resection was counted. More patients underwent Robotic-Assisted procedures (72 versus 40 ), and a slightly higher proportion of Robotic-Assisted procedure patients underwent anatomic pulmonary resection 54/72 (75\%) compared with VATS patients 26/40 (65\%). There were 133 identified air leaks, among 112 subjects. In the majority of cases only one application of sealant was required to treat identified intraoperative air leaks 108/133 (81.2\%).

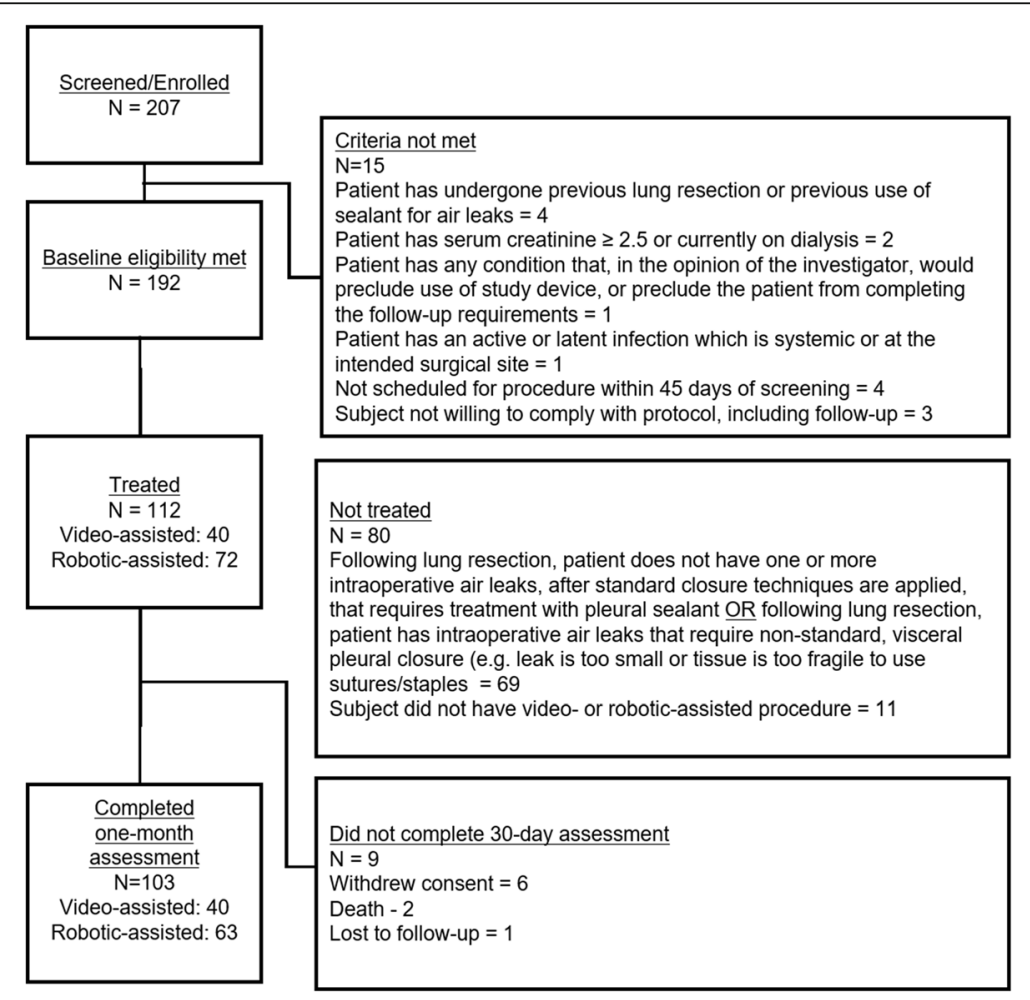

Fig. 2 Disposition of patients and primary reasons patients were screened but not treated 
Table 1 Patient Characteristics

\begin{tabular}{|c|c|c|}
\hline Characteristic & All Patients $(n=112)$ & Percent (\%) \\
\hline \multicolumn{3}{|l|}{ Gender } \\
\hline Male & 46 & 41 \\
\hline Female & 66 & 59 \\
\hline Median age in years (range) & $69(34-87)$ & \\
\hline \multicolumn{3}{|l|}{ Comorbid Conditions } \\
\hline Hypertension & 64 & \\
\hline Diabetes & 17 & \\
\hline Renal disease & 10 & \\
\hline Previous myocardial infarction & 7 & \\
\hline Cardiovascular disease & 37 & \\
\hline History of stroke & 4 & \\
\hline History of transient ischemic attack & 4 & \\
\hline Congestive heart failure & 5 & \\
\hline COPD & 34 & \\
\hline Alcohol abuse (Past and Current) & 11 & \\
\hline \multicolumn{3}{|l|}{ Diagnosis/Indications for surgery } \\
\hline Primary tumor & 96 & 86 \\
\hline Metastatic tumor & 5 & 4 \\
\hline Lung nodule & 7 & 6 \\
\hline Other ${ }^{a}$ & 4 & 4 \\
\hline \multicolumn{3}{|l|}{ Smoking History } \\
\hline Never & 31 & 27 \\
\hline Current & 21 & 19 \\
\hline Former & 60 & 54 \\
\hline \multicolumn{3}{|l|}{ Pulmonary function tests $(n=101)$} \\
\hline $\mathrm{FEV}_{1} \%$ predicted $($ mean $\pm \mathrm{SD})$ & $81.2 \pm 24.3$ & \\
\hline FVC $\%$ predicted (mean \pm SD) & $86.0 \pm 25.5$ & \\
\hline DLCO $\%$ predicted $($ mean \pm SD) & $70.9 \pm 25.0$ & \\
\hline
\end{tabular}

COPD chronic obstructive pulmonary disease, $F E V_{1}$ forced expiratory volume in $1 \mathrm{~s}$, FVC forced vital capacity, DLCO diffusing capacity of carbon monoxide a Other diagnosis include: COPD, chronic bronchitis, aspergilloma, bleb

Table 2 Perioperative Details

\begin{tabular}{llll}
\hline & $n=112$ & VATS $(n=40)$ & $\begin{array}{l}\text { Robotic-Assisted } \\
(n=72)\end{array}$ \\
\hline $\begin{array}{l}\text { Operative procedures } \\
\text { a }\end{array}$ & 29 & 14 & 15 \\
Wedge resection & 29 & 4 & 9 \\
Legmentectomy & 13 & 21 & 40 \\
Bilobectomy & 61 & 1 & 5 \\
$\begin{array}{l}\text { Decortication } \\
\text { Biopsy }\end{array}$ & 2 & 0 & 2 \\
$\begin{array}{l}\text { Median OR time, } \\
\text { minutes (range) }\end{array}$ & $214.5(79-433)$ & 0 & 1 \\
\hline VATS video-assisted thotic surger, OR operting rom &
\end{tabular}

VATS video-assisted thoracic surgery, OR operating room aEleven subjects had more than one procedure; only the most extensive procedure was counted

\section{Morbidity}

There were no observed device-related adverse events. The overall complication rate for the entire treated group was $41 \%$ (46/112). Major complications, as defined as NCI CTCAE (v4.03) [18] grade 3 or higher adverse events, occurred in 18 patients (16.1\%) (Table 3). Prolonged air leak was the most common single major adverse event, occurring in 10 patients $(8.9 \%)$. Of the 10 patients with prolonged air leak, six were considered major because they required additional intervention, such as insertion of an additional chest tube or chemical pleurodesis. Two such patients underwent reoperation - one had bleb resection, and one had creation of a pleural tent. An additional 5 patients underwent reoperation for indications including postoperative hemorrhage, pulmonary torsion, and repair of bronchopleural fistula, for a total reoperation rate of $6.3 \%(7 / 112)$.

In-hospital mortality and 30-day mortality were each $1.9 \%$ (2/103). One patient underwent Robotic-Assisted lobectomy and developed right upper lobe torsion necessitating reoperation. Postoperatively the patient suffered sudden cardiac arrest and expired on postoperative day 13. The second patient underwent Robotic-Assisted lobectomy and suffered aspiration pneumonitis on postoperative day 2 . This progressed to acute respiratory distress and multi-system organ failure. The patient had withdrawal of care and died on postoperative day 11.

There were a total of 133 intraoperative air leaks identified in 112 patients (Table 4). The most common site of leak was from the area of the staple line (98/133, $74 \%)$. The median number of applications of sealant was 1 (range $1-3)$, and $80 \%(107 / 133)$ of leaks were sealed at

Table 3 Major Complications ${ }^{a}$

\begin{tabular}{lr}
\hline Prolonged air leak & 6 \\
Postoperative hemorrhage & 3 \\
Pleural effusion & 2 \\
Acute respiratory distress syndrome & 2 \\
Pneumothorax & 1 \\
Pulmonary torsion & 1 \\
Bronchopleural fistula & 1 \\
Pericardial effusion & 1 \\
Subcutaneous emphysema & 1 \\
Aspiration pneumonitis & 1 \\
Cardiac arrest & 1 \\
Pneumonia & 1 \\
Positive resection margin & 1 \\
Multi-organ failure & 1 \\
Total & 1 \\
\hline
\end{tabular}

Terminology Criteria for Adverse Events (v4.03)

a Major complications defined as Grade 3 or higher as per National Cancer Institute Common 
Table 4 Intraoperative Air Leaks (IOAL)

\begin{tabular}{lll}
\hline Variable & Number of Air Leaks $(n=133)$ & Percent $(\%)$ \\
\hline Source of air leak & & 6.7 \\
Suture line & 9 & 73.8 \\
Staple line & 98 & 9.0 \\
Lung surface & 12 & 3.8 \\
Torn lung & 5 & 6.7 \\
Fissure & 9 & \\
Final assessment of IOAL & 3.8 \\
Not sealed & 5 & 15.8 \\
Reduced & 21 & 80.4 \\
Sealed & 107 & \\
\hline
\end{tabular}

the time of operation, while another 21 (16\%) were reduced. Postoperatively, $61 \%$ of patients had no leak in the post-anesthesia care unit, and $49 \%$ of patients demonstrated no air leak up through the 1 month postoperative visit (Table 5). The median chest tube duration was 2 days (range $1-46$ ), and the median length of stay for the entire cohort was 3 days (range $1-20$ ). Eight patients were discharged with a chest tube in place and had removal in the outpatient setting.

\section{Discussion}

This is the first study, prospective or otherwise, evaluating the feasibility of utilizing lung sealant following minimally invasive lung resection. It demonstrated that the use of Progel ${ }^{\mathrm{TM}}$ PALS was safe, with no device-related morbidity and with overall major procedural morbidity rates that were consistent with similar large series of VATS and Robotic-Assisted lung resections [3, 4, 6, 7]. Boffa and co-authors recently reported results of a retrospective study of VATS versus open anatomic lung resections from 11,531 patients in the voluntary Society of Thoracic Surgeons database [19]. The overall

Table 5 Comparative Efficacy of Proge ${ }^{T M}$ PALS in MIS and Open Studies

\begin{tabular}{|c|c|c|c|}
\hline \multirow[b]{2}{*}{ Endpoint } & \multirow{2}{*}{$\begin{array}{l}\text { Current Study } \\
\text { MIS Treatment } \\
\text { Group }\end{array}$} & \multicolumn{2}{|c|}{$\begin{array}{l}\text { Progel }^{\mathrm{TM}} \text { PALS Open } \\
\text { Study [17] }\end{array}$} \\
\hline & & $\begin{array}{l}\text { Treatment } \\
\text { Group }\end{array}$ & Control \\
\hline Air leaks sealed in the OR & $80 \%$ & $77 \%$ & $16 \%$ \\
\hline $\begin{array}{l}\text { Air leaks sealed immediately } \\
\text { following surgery }\end{array}$ & $60.7 \%$ & $54 \%$ & $33 \%$ \\
\hline $\begin{array}{l}\text { Air leaks sealed through } \\
1 \text { month post-operative }\end{array}$ & $49.1 \%$ & $35 \%$ & $14 \%$ \\
\hline $\begin{array}{l}\text { Median duration of post-op } \\
\text { air leakage }\end{array}$ & 1.0 day & 2 days & 2 days \\
\hline Median chest tube duration & 2.0 days & 5 days & 5 days \\
\hline Median length of stay & 3.0 days & 6 days & 7 days \\
\hline
\end{tabular}

MIS minimally invasive surgery, PALS pleural air leak sealant, OR operating room complication rate for VATS was 30\%, with an operative mortality rate of $1.3 \%$. By comparison, in our study the overall morbidity was $41 \%$ with an operative mortality rate of $1.9 \%$. Taking into account the prospective nature of the current study, the results are acceptable. In addition, the observed chest tube duration and length of stay were substantially shorter than the comparable data from the previous randomized trial (Table 5).

To date, this is the only experience in a cohort undergoing exclusively minimally invasive thoracic surgery. The previous prospective, randomized trial that demonstrated efficacy of this solitary FDA-approved product to seal intraoperative air leaks and reduce length of stay was almost exclusively in patients undergoing thoracotomy [17]. Two other prospective, randomized studies of an alternative polyethylene glycol matrix (currently not approved for use in the United States) were conducted as adjuncts to predominantly open approaches [20, 21]. In the more recent report, while the authors stated that some proportion of procedures were performed by VATS, they did not report the distribution of surgical approach [21].

The secondary endpoints observed regarding the efficacy of the sealant were also promising and consistent with the prior efficacy study (Tables 4 and 5). Intraoperative air leaks were sealed $(21 / 133,15.8 \%)$ or reduced $(107 / 133,80.4 \%)$ in $96.2 \%$ of cases, and $49 \%$ of the patients had no evidence of air leak through 1-month of postoperative follow-up. This compares favorably with the results reported by Allen and colleagues, who observed that $35 \%$ of patients experienced freedom from air leak throughout the entire 1-month follow-up, versus only $14 \%$ of the control group. Similarly, Klijian performed a retrospective review of a single institution experience comparing patients undergoing lung resection who received intraoperative pleural sealant with those who did not [22]. In individuals with intraoperative air leak, the use of sealant was associated with a significant decrease in the incidence of postoperative air leak $(11 \%$ in the sealant group versus $58.8 \%$ in the control group, $p<0.0001)$ as well as shorter chest tube duration and hospital stay.

The strengths of the current study include the prospective multicenter design, rigorous prospective documentation of potential product- and procedural-related complications, and the standardization of intraoperative air leak assessment and subsequent treatment. In particular, the requirement that patients must have a demonstrable intraoperative air leak to be treated, while not necessary to determine the safety of the product, eliminated unnecessary treatment and allowed for evaluation of secondary efficacy outcomes.

There are some limitations of this report. The treatment population was somewhat heterogeneous, with a 
mixture of patients undergoing non-anatomic and anatomic resection, as well as different minimally invasive approaches (VATS and Robotic-Assisted). Moreover, without a control group undergoing only standard methods to prevent air leak, conclusions about the efficacy of the sealant by comparison to historical data is limited. A followup study utilizing a prospective, randomized case-control methodology to more rigorously evaluate efficacy would be ideal. Included in the study should be a planned cost-effectiveness analysis as well, to determine whether any potential clinical benefit also has an acceptable cost profile.

\section{Conclusions}

The use of PEG cross-linked with human serum albumin as a pneumostatic agent for patients with intraoperative air leak following minimally invasive pulmonary resection is safe and efficacious. In addition, its use does not appear to be associated with increased procedural morbidity or mortality. Based upon the results of the study, the product's use was observed to reduce intraoperative air leak and should be considered for use on pleural air leaks identified during lung resection in open or minimally invasive procedures.

\footnotetext{
Abbreviations

CXR: Chest roentgenogram; MIS: Minimally invasive surgery; VATS: Video-assisted thoracic surgery; STS: Society of thoracic surgery; PEG: Polyethylene glycol; FDA: Federal drug administration; IOAL: Intraoperative air leak; POAL: Postoperative air leak; AEs: Adverse events; PG: Performance goal; CFR: Code of federal regulations; NCI CTCAE: National cancer institute common terminology for clinical adverse events
}

\section{Acknowledgements}

N/A

\section{Funding}

This study was sponsored by C. R. Bard, Inc. (Davol), Warwick RI. The authors and/or affiliated institutions were compensated for participation in this study (BJ Park, JM Snider, NR Bates, SD Cassivi, GK Jett, JR Sonett and EM Toloza). This work was also supported, in part, by $\mathrm{NIH} / \mathrm{NCl}$ Cancer Center Support Grant P30 CA008748.

\section{Availability of data and materials}

Please contact author for data requests.

\section{Authors' contributions}

BJP: Principal Investigator, study concept, study design, data acquisition/ analysis/interpretation, and manuscript preparation. JMS: Study design, Data acquisition/interpretation, and Manuscript review. NRB: Study design, Data acquisition/interpretation, and Manuscript review. SDC: Study design, Data acquisition/interpretation. GKJ: Study design, Data acquisition/interpretation, and Manuscript review. JRS: Study design, Data acquisition/interpretation, and Manuscript review. EMT: Study design, Data acquisition/interpretation, and Manuscript review. All authors read and approved the final manuscript.

\section{Competing interests}

This study was sponsored by C. R. Bard, Inc. (Davol), Warwick, Rl. The authors and/or affiliated institutions were compensated for participation in this study (BJ Park, JM Snider, NR Bates, SD Cassivi, GK Jett, JR Sonett, and EM Toloza).

\section{Consent for publication}

N/A.

\section{Ethics approval and consent to participate}

This study was conducted in compliance with the United States Code of Federal Regulations (CFR), 21 CFR Part 812, Investigational Device Exemptions, Part 56, Institutional Review Boards, Part 50, Protection of Human Subjects, and the ethical principles that have their origin in the Declaration of Helsinki. Institutional review boards at each institution approved the clinical trial prior to initiation of the study. Informed consent was obtained in writing from all patients.

\section{Disclosures}

This study was sponsored by C. R. Bard, Inc. (Davol), Warwick Rl. The authors and/or affiliated institutions were compensated for participation in this study (BJ Park, JM Snider, NR Bates, SD Cassivi, GK Jett, JR Sonett and EM Toloza). This work was also supported, in part, by $\mathrm{NIH/NCl}$ Cancer Center Support Grant P30 CA008748.

\section{Author details}

${ }^{1}$ Memorial Sloan Kettering Cancer Center, 1275 York Avenue, Box 531, New York, NY 10065, USA. ${ }^{2}$ Mercy Health System, Janesville, WI, USA.

${ }^{3}$ Cardiothoracic \& Vascular Surgical Associates, Jacksonville, FL, USA. ${ }^{4}$ Mayo Clinic, Rochester, MN, USA. ${ }^{5}$ The Heart Hospital Baylor Plano, Plano, TX, USA. ${ }^{6}$ New York-Presbyterian Hospital, Columbia University, New York, NY, USA. ${ }^{7}$ H. Lee Moffitt Cancer Center and Research Institute, Tampa, FL, USA.

Received: 23 June 2016 Accepted: 6 December 2016

Published online: 12 December 2016

\section{References}

1. Siegel RL, Miller KD, Jemal A. Cancer statistics, 2015. CA Cancer J Clin. 2015;65(1):5-29. doi:10.3322/caac.21254.

2. Varela G, Jimenez MF, Novoa N, Aranda JL. Estimating hospital costs attributable to prolonged air leak in pulmonary lobectomy. Eur J Cardiothorac Surg. 2005;27(2):329-33. doi:10.1016/j.ejcts.2004.11.005

3. McKenna Jr RJ, Houck W, Fuller CB. Video-assisted thoracic surgery lobectomy: experience with 1,100 cases. Ann Thorac Surg. 2006;81(2):421-5. doi:10.1016/j.athoracsur.2005.07.078. discussion 5-6.

4. Onaitis MW, Petersen RP, Balderson SS, Toloza E, Burfeind WR, Harpole Jr DH, et al. Thoracoscopic lobectomy is a safe and versatile procedure: experience with 500 consecutive patients. Ann Surg. 2006;244(3):420-5. doi:10.1097/01.sla. 0000234892.79056.63.

5. Cattaneo SM, Park BJ, Wilton AS, Seshan VE, Bains MS, Downey RJ, et al. Use of video-assisted thoracic surgery for lobectomy in the elderly results in fewer complications. Ann Thorac Surg. 2008;85(1):231-5. doi:10.1016/j. athoracsur.2007.07.080. discussion 5-6.

6. Flores RM, Park BJ, Dycoco J, Aronova A, Hirth Y, Rizk NP, et al. Lobectomy by video-assisted thoracic surgery (VATS) versus thoracotomy for lung cancer. J Thorac Cardiovasc Surg. 2009;138(1):11-8. doi:10.1016/j.jtcvs.2009.03.030.

7. Park BJ, Melfi F, Mussi A, Maisonneuve P, Spaggiari L, Da Silva RK, et al. Robotic lobectomy for non-small cell lung cancer (NSCLC): long-term oncologic results. J Thorac Cardiovasc Surg. 2012;143(2):383-9. doi:10.1016/j. jtcvs.2011.10.055.

8. Ceppa DP, Kosinski AS, Berry MF, Tong BC, Harpole DH, Mitchell JD, et al. Thoracoscopic lobectomy has increasing benefit in patients with poor pulmonary function: a society of thoracic surgeons database analysis. Ann Surg. 2012;256(3):487-93. doi:10.1097/SLA.0b013e318265819c.

9. Cerfolio RJ, Tummala RP, Holman WL, Zorn GL, Kirklin JK, McGiffin DC, et al. A prospective algorithm for the management of air leaks after pulmonary resection. Ann Thorac Surg. 1998;66(5):1726-31.

10. Rice T, Kirby T. Prolonged air leak. Chest Clin North Am. 1992;2:803-10.

11. Wright CD, Wain JC, Grillo HC, Moncure AC, Macaluso SM, Mathisen DJ. Pulmonary lobectomy patient care pathway: a model to control cost and maintain quality. Ann Thorac Surg. 1997;64(2):299-302. doi:10.1016/S00034975(97)00548-1.

12. Fleisher AG, Evans $K G$, Nelems B, Finley RJ. Effect of routine fibrin glue use on the duration of air leaks after lobectomy. Ann Thorac Surg. 1990;49(1):133-4.

13. Mouritzen C, Dromer M, Keinecke HO. The effect of fibrin glueing to seal bronchial and alveolar leakages after pulmonary resections and decortications. Eur J Cardiothorac Surg. 1993;7(2):75-80.

14. Wong K, Goldstraw P. Effect of fibrin glue in the reduction of postthoracotomy alveolar air leak. Ann Thorac Surg. 1997;64(4):979-81. 
15. Wain JC, Kaiser LR, Johnstone DW, Yang SC, Wright CD, Friedberg JS, et al. Trial of a novel synthetic sealant in preventing air leaks after lung resection. Ann Thorac Surg. 2001;71(5):1623-8. discussion 8-9.

16. Kobayashi H, Sekine T, Nakamura T, Shimizu Y. In vivo evaluation of a new sealant material on a rat lung air leak model. J Biomed Mater Res. 2001;58(6):658-65.

17. Allen MS, Wood DE, Hawkinson RW, Harpole DH, McKenna RJ, Walsh GL, et al. Prospective randomized study evaluating a biodegradable polymeric sealant for sealing intraoperative air leaks that occur during pulmonary resection. Ann Thorac Surg. 2004;77(5):1792-801. doi:10.1016/j.athoracsur. 2003.10.049.

18. US Dept of Health and Human Services, National Institutes of Health, National Cancer Institute. Common Terminology Criteria for Adverse Events (CTCAE) v4.03. 2010.

19. Boffa DJ, Dhamija A, Kosinski AS, Kim AW, Detterbeck FC, Mitchell JD, et al. Fewer complications result from a video-assisted approach to anatomic resection of clinical stage I lung cancer. J Thorac Cardiovasc Surg. 2014;148(2):637-43. doi:10.1016/j.jtcvs.2013.12.045.

20. D'Andrilli A, Andreetti C, Ibrahim M, Ciccone AM, Venuta F, Mansmann U, et al. A prospective randomized study to assess the efficacy of a surgical sealant to treat air leaks in lung surgery. Eur J Cardiothorac Surg. 2009;35(5):817-20. doi:10.1016/j.ejcts.2009.01.027. discussion 20-1.

21. Lequaglie C, Giudice G, Marasco R, Morte AD, Gallo M. Use of a sealant to prevent prolonged air leaks after lung resection: a prospective randomized study. J Cardiothorac Surg. 2012;7:106. doi:10.1186/1749-8090-7-106.

22. Klijian A. A novel approach to control air leaks in complex lung surgery: a retrospective review. J Cardiothorac Surg. 2012;7:49. doi:10.1186/1749-8090-7-49.

\section{Submit your next manuscript to BioMed Central and we will help you at every step:}

- We accept pre-submission inquiries

- Our selector tool helps you to find the most relevant journal

- We provide round the clock customer support

- Convenient online submission

- Thorough peer review

- Inclusion in PubMed and all major indexing services

- Maximum visibility for your research

Submit your manuscript at www.biomedcentral.com/submit
Biomed Central 